\title{
¿Desindustrialización prematura? El caso de Nuevo León, México
}

Belem Iliana Vásquez Galán*y Salyador Corrales Corrales**

\section{RESUMEN}

El objetivo del artículo es analizar el proceso de desindustrialización ocurrida en la industria nacional mexicana y en particular en la de Nuevo León en el periodo 1993-2016. Se calculó la participación de la industria manufacturera en la creación de valor agregado real y empleos, la velocidad del cambio estructural y el ingreso per cápita para identificar el momento y naturaleza de la desindustrialización. Se encontró una desindustrialización prematura iniciada a finales de los noventa con el cambio estructural desfavorable ocurrido por la caída de la participación industrial en la economía y los bajos ingresos per cápita. A diferencia de la experiencia nacional, en Nuevo León se gestó una desindustrialización natural resultado de la evolución de su industria, de tradicional (vidrio, acero y cemento) a moderna (eléctrica y electrónica y automotriz) y que sentó las bases para transitar a una economía terciaria.

Palabras clave: industria, desindustrialización, manufacturas, empleo. Clasificación JEL: O14, L60, J21.

\section{ABSTRACT}

\section{Premature deindustrialization? The case of Nuevo Leon, Mexico}

The aim of this article is to analyze the process of deindustrialization in Mexico and particularly in Nuevo Leon in the period 1993-2016. The share of manufactures in total valued added and employment was calculated, as well as the speed of structural change and the income

\footnotetext{
*El Colegio de la Frontera Norte A.C., México. Correo-e: belem@colef.mx.

*** El Colegio de la Frontera Norte A.C., México. Correo-e: corrales@colef.mx.
} 
per capita in order to identify when and what type of deindustrialization occurred. We found that the deindustrialization was premature and started at the end of the nineties when the industry reduced its share in the economy while the income per capita was still low. Contrary to the national situation, deindustrialization in Nuevo Leon was a natural process that happened due to the industry's evolution from traditional (glass, steel and cement) to modern activities (electric, electronic and automobile), so the transition to a tertiary economy was accompanied by an industrial base.

Keywords: Industry, deindustrialization, manufactures, employment. JEL Clasiffication: O14, L60, J21.

\section{INTRODUCCIÓN}

La industria manufacturera regiomontana tiene una larga tradición en la producción de acero, cemento, vidrio, plásticos y autopartes. A nadie le parecerá extraña la enorme importancia de las cervecerías junto con las fábricas de acero, eje fundamental del crecimiento industrial desde mediados del siglo pasado (Nuncio, 1982; Cerutti, 2000). En la actualidad, la posición relativa de las manufacturas en la composición del producto estatal bruto de Nuevo León las coloca lejos del liderazgo económico regional, lo que sugiere que existe un proceso de desindustrialización donde las actividades comerciales y de servicios parecen definir el futuro económico del estado. ¿Ha sido Nuevo León presa de una desindustrialización prematura o natural? ¿Cuál es la posición relativa del estado respecto a la tendencia de la industria nacional?

La desindustrialización se describe como un fenómeno en el cual la participación relativa de las manufacturas en el empleo total se reduce $y$, en economías avanzadas, es resultado del aumento de la productividad en las manufacturas (Rowthorn y Ramaswany, 1997). La notoria caída de las actividades industriales en una región como Nuevo León, que se caracterizó por tener las empresas más importantes de productos manufactureros y la proliferación de las actividades terciarias, requiere explicaciones desde diferentes ángulos para entender este fenómeno que mantiene contrariados a propios y a extraños. El objetivo de este artículo es identificar el momento en que empieza el proceso de desindustrialización en México, con énfasis en el estado de Nuevo León, 
cuna de la industrialización del país, y determinar si ésta fue prematura o alcanzó el grado de madurez requerida para transitar a una economía predominantemente terciaria. Para ello se calcularon tres indicadores que miden el grado de desindustrialización de una economía y que han sido ampliamente abordados en la literatura (Schiavo-Campo, 1978; Rodrik, 2016; Dasgupta y Singh; 2006, entre otros). Los indicadores que se calcularon fueron la participación de las manufacturas en el valor agregado real, la participación de las manufacturas en el empleo total y el índice de cambio estructural, con base en datos anuales de 1993 a 2016. El tipo de desindustrialización se determinó a partir de relacionar el ingreso per cápita alcanzado con el máximo porcentaje de participación del valor agregado manufacturero en la economía. La hipótesis planteada es que en México el proceso de desindustrialización se manifiesta a finales de la década de los noventa, con la pérdida de participación de la industria en el empleo y en el valor agregado real. Sin embargo, a diferencia de la experiencia nacional, en Nuevo León se gestó una desindustrialización con mayores tasas de participación en el valor agregado, el empleo y con un ingreso per cápita más alto. Consideramos que la desindustrialización en este estado fue resultado de un proceso natural de maduración donde las actividades industriales tradicionales (de vidrio, acero y cemento) perdieron participación en la economía en comparación con las actividades industriales modernas (la electrónica, eléctrica, autopartes, etcétera).

El artículo se compone de cinco apartados, además de la introducción. En el segundo apartado se expone la explicación de la teoría sobre el fenómeno de la desindustrialización generada en los países que han transitado a economías terciarias. En el tercer apartado se hace un análisis de la trayectoria de la industria manufacturera en México y Nuevo León. En el cuarto apartado se presenta una explicación del marco metodológico empleado para comprobar e identificar la naturaleza de la desindustrialización en México y en particular en Nuevo León. En el quinto apartado se muestran los resultados y en el sexto se presentan las conclusiones. 


\section{LA TEORÍA DE LA DESINDUSTRIALIZACIÓN}

El desarrollo de las economías es resultado del crecimiento entre los sectores que la constituyen, cuya capacidad de respuesta a los avances tecnológicos se presenta muy desigual y en función de la complejidad del producto final. Desde la introducción del motor a vapor, hasta el desarrollo de la computación, la industria ha sido la principal fuente del crecimiento, con excepción de algunos países de África subsahariana, donde la agricultura y la ganadería todavía son los componentes principales de sus economías. Hablar de desarrollo de las economías implica entender todos sus sectores de actividad económica, cuya participación en la composición del Producto Interno Bruto (PIB) es desigual y dependiente del nivel tecnológico con que operan (Castillo y Martins, 2016).

Si partimos de que el crecimiento y el desarrollo de los países está fundamentado en la industrialización de su proceso de producción, una de las formas de medir su riqueza es a través del grado de industrialización alcanzado. En este sentido, la revolución industrial dio origen al crecimiento acelerado de los países porque la mecanización permitió aumentar la productividad de factores como el trabajo y el capital. Aquellos países que contaron con máquinas en sus fábricas empezaron a tener ventajas y crecimiento mayor que los países que carecieron o las introdujeron más tarde. Las naciones que experimentaron la primera revolución industrial pasaron por diferentes etapas, durante las que la industrialización evolucionó e integró, primero, la automatización, la producción en serie y la tecnología. En cada etapa, la productividad y las economías a escala permitieron producir más con menos, por lo que cada vez se requería menos trabajo para producir manufacturas y más para realizar actividades de comercio y servicios. Con el desarrollo de la industria, la agricultura se colocó en un segundo plano. El desarrollo tecnológico en la industria redujo dramáticamente el empleo debido a la introducción de maquinaria, lo que propició el desplazamiento hacia el comercio y los servicios como opciones de empleo y generación de ingresos.

Los países que alcanzaron un alto nivel de desarrollo redujeron su sector agrícola e hicieron crecer la industria, la cual absorbió la fuerza de trabajo desplazada del campo, hecho que ocasionó que mejorara su nivel de ingreso per cápita. Con mayor crecimiento económico, el 
aumento del ingreso per cápita modificó los hábitos de consumo de la población, expandió el comercio y los servicios en la composición de la economía nacional. Con el desarrollo tecnológico y de posicionamiento de los sectores económicos que componen una economía, los países más avanzados entraron en un proceso de desindustrialización en el empleo y en el valor agregado. Los altos niveles del ingreso per cápita de estas economías incrementaron la demanda del comercio y los servicios, ya que una sociedad con mayor capacidad de consumo requiere satisfacer una gama mayor de necesidades, como servicios educativos, legales, médicos y servicios dirigidos a los productores.

La creciente automatización de la industria ha inducido el desplazamiento de trabajadores hacia el comercio y los servicios, donde un alto porcentaje opta por la informalidad. Esta situación ha motivado numerosas investigaciones en búsqueda de soluciones estructurales de la economía para mejorar el crecimiento económico (Rivera, 2014; Schneider et al., 2010; Kaufman y Kaliberda, 1996). La pérdida de importancia de la industria en la composición del empleo y el producto en países desarrollados es comprensible para muchos economistas, dado el nivel del ingreso per cápita de la población (Rodrik, 2016; Mcmillan et al., 2014). Lo incomprensible es la fuerte presencia del comercio y los servicios en los países subdesarrollados que aún no han alcanzado ingresos per cápita suficientemente altos. En la literatura existen estudios que intentan encontrar las razones por las cuales algunos países en desarrollo se están desindustrializando tan temprano (Camacho y Maldonado, 2018).

La desindustrialización, concepto atribuido a Rowthorn y Ramaswany (1997), es la pérdida de participación de las manufacturas en el empleo total cuando se alcanza un cierto ingreso per cápita. Posteriormente, Tregenna (2009) propuso medir la desindustrialización también en términos de la pérdida de participación de las manufacturas en el valor agregado, ya que una economía puede perder trabajo manufacturero y al mismo tiempo aumentar su participación en el valor agregado. Esto implica que la desindustrialización puede ser el resultado del aumento de la productividad laboral y, por lo tanto, ser un fenómeno deseable. Desde el punto de vista de los países ricos, el cambio ocurre cuando se alcanza un nivel de ingreso per cápita relativamente alto, ya que, con mayores ingresos, la demanda de servicios empieza a ser mayor que la de manufacturas. Para satisfacer la alta demanda 
de servicios, los recursos productivos se distribuyen de tal forma que la producción de bienes tangibles empieza a perder peso relativo en la economía. De acuerdo con Palma (2005), existen cuatro hipótesis que explican la caída del empleo manufacturero en los países desarrollados, ocurrida a finales de los sesenta. La primera hipótesis afirma que se trata de una ilusión estadística creada por el aumento de la demanda que la misma industria manufacturera hace de servicios profesionales; la segunda hipótesis lo atribuye a la disminución de la elasticidad-ingreso de la demanda de manufacturas; la tercera hipótesis considera que la nueva división internacional del trabajo ha desplazado las manufacturas a países menos desarrollados, por lo que los países ricos han dejado de producir manufacturas; la cuarta hipótesis, que es la más generalizada, explica la desindustrialización como el resultado de las ganancias de productividad laboral generadas en la industria manufacturera.

Al economista Dani Rodrik se le atribuye el concepto de desindustrialización prematura, usado para explicar el comportamiento de la industria en muchos países en desarrollo y de África subsahariana (Rodrik, 2016). Con un método aplicado, compagina variables en sus estimaciones y análisis, como la tecnología, el ingreso per cápita, el empleo y el ingreso, para explicar las diferencias entre países con diferentes niveles de industrialización. Se identifica la desindustrialización como un proceso que ocurre cuando hay una pérdida de participación de las manufactureras, específicamente en el empleo y en el valor de la producción total. El proceso que se genera de manera natural da lugar a la desindustrialización de la economía. Cuando se genera una desindustrialización sin haber logrado un nivel de ingreso per cápita suficientemente alto, significa que el tránsito hacia una economía terciaria ocurre antes que lo deseado, como ocurrió con los países desarrollados. A este proceso se le conoce como desindustrialización temprana o prematura.

Según Rodrik (2016), la evidencia indica que los países en desarrollo se han convertido en economías terciarias sin haber completado el proceso de industrialización, como lo hicieron los primeros países industrializados de Europa. Esta situación propicia que se vulnere el principal mecanismo para lograr un crecimiento económico rápido. La política de industrialización mediante la sustitución de importaciones aplicada en la década de los cuarenta, y que se sostuvo hasta la década de los setenta, logró que muchos países en desarrollo de Latinoamérica lograran altas tasas de crecimiento, pero sin bases tecnológicas 
y de capital suficientes para competir a nivel internacional (Vázquez, 2017). El abandono de la política de industrialización por una política de crecimiento basada en las exportaciones en la década de los ochenta ocasionó que muchos países se volvieran importadores netos de manufacturas. La razón es que muchos países en desarrollo carecían de ventajas comparativas que les permitieran competir en el mercado internacional cuando las restricciones al comercio internacional se redujeron. La apertura comercial promovida por organismos internacionales fue responsable no sólo de que se detuviera el proceso de industrialización sino de que los países en vías de desarrollo importaran la desindustrialización de los países desarrollados, pues tuvieron que competir con productos manufacturados que ya contaban con precios relativos bajos gracias a su mayor productividad (Rodrik, 2016: 4).

El proceso de desindustrialización en países de bajo nivel de desarrollo, como México, se empieza a gestar por la apertura comercial de los años ochenta que se materializa con el ingreso al Acuerdo General sobre Aranceles Aduaneros y Comercio (GATT, por sus siglas en inglés) y después con el ingreso al Tratado de Libre Comercio de América del Norte (TLCAN) en la década de los noventa. La apertura a la competencia internacional modificó las cadenas productivas nacionales mediante una fuerte penetración de manufacturas y productos intermedios de Estados Unidos. Competir con la industria manufacturera norteamericana no fue fácil; la industria mexicana tuvo que acoplarse mediante prácticas de comercio intra-firma y procesos de subcontratación industrial, que modificaron la contabilidad de las fábricas. El creciente comercio intra-firma y la subcontratación industrial redujeron el valor agregado de la industria para pasar la contabilidad al sector servicios (Silva-Colmenares, 2014). Trabajos recientes, como el de Castillo y Martins (2016), indican que algunos países latinoamericanos, como Argentina, Brasil, Chile y México, enfrentan una desindustrialización prematura desde la década de los noventa, la cual se manifiesta como un incremento de la especialización en bienes primarios, manufacturas basadas en recursos naturales y servicios de baja productividad. Los autores muestran, mediante un análisis de Shift and Share, que el crecimiento de la productividad laboral se reduce conforme las economías experimentan un cambio estructural, en el que las actividades manufactureras pierden participación mientras los servicios la ganan. Aunque Rowthorn y Ramaswany (1997) afirman que la desindustrialización no 
es un fenómeno negativo, ya que es resultado del rápido crecimiento de la productividad de las manufactureras, reconocen que incluso bajo estas condiciones, en el largo plazo, la productividad general de la economía estará determinada por el crecimiento de la productividad de los servicios. Por su naturaleza, los servicios son altamente heterogéneos $\mathrm{y}$, por lo tanto, menos progresivos tecnológicamente hablando en comparación con las manufacturas. El resultado es que conforme las economías se vuelven más terciarizadas, el crecimiento económico dependerá del crecimiento de la productividad de los servicios, no de las manufacturas.

\section{LA TRANSFORMACIÓN DE LA INDUSTRIALIZACIÓN EN MÉXICO Y EN NUEVO LEÓN}

En México, la industria comprende las actividades manufactureras clasificadas en 22 grupos del sector secundario, ${ }^{1}$ por lo que existe gran heterogeneidad en el tipo de procesos productivos que realizan. Con cifras oficiales del INEGI, en términos de valor agregado real (a precios de 2013), las manufacturas han mantenido una baja participación en la economía desde 1993 e incluso han reducido la generación de valor agregado. En 2017 representaron apenas 16.6\% del valor total, mientras que los servicios, 65.6 por ciento. Al igual que muchos países, en México las actividades terciarias generan el mayor valor agregado en la economía, ya que concentran actividades que incluyen servicios especializados que, al tener alto contenido de conocimiento y tecnología, su aportación al valor agregado es relativamente alta.

En el caso de México, la política industrial permitió que en los años sesenta las manufacturas tuvieran una participación creciente en el PIB

\footnotetext{
De acuerdo con la clasificación del INEGI, las industrias manufactureras comprenden a: industria alimentaria; industria de las bebidas y del tabaco; fabricación de insumos textiles; confección de productos textiles; fabricación de prendas de vestir; fabricación de productos de cuero, piel y materiales sucedáneos; Industria maderera; industria del papel; impresión e industrias conexas; fabricación de productos derivados del petróleo y del carbón; industria química; industria del plástico y del hule; fabricación de productos a base de minerales no metálicos; industrias metálicas básicas; fabricación de productos metálicos; fabricación de maquinaria y equipo; fabricación de equipo de computación, comunicación, medición y de otros, componentes y accesorios electrónicos; fabricación de equipo de generación eléctrica y aparatos y accesorios eléctricos; fabricación de equipo de transporte; fabricación de muebles y productos relacionados y otras manufacturas.
} 
nacional. En la Figura 1 se presenta la trayectoria de las manufactureras de 1965 a 2016 en términos de participación en el valor agregado corriente. Se distingue el momento en que empieza la desindustrialización o caída de la participación de las manufacturas. Por ejemplo, a finales de los sesenta la industria mostraba una participación creciente en la economía; aumentó de $18.7 \%$, en 1965 , a $22 \%$, en 1970 . Este patrón se mantuvo y alcanzó el máximo porcentaje de participación en 1983 con $22.1 \%$. A partir de entonces, con la apertura comercial y liberalización de la economía, ocurrida en 1986, la industria empieza a perder peso en la economía. Sólo en 1997 tuvo un repunte como resultado de dos eventos coyunturales: la entrada en vigor del TLCAN y la devaluación del peso mexicano en 1994 que incrementó la demanda de productos mexicanos en el exterior.

FIGURA 1

PARTICIPACIÓN DEL VALOR AGREGADO MANUFACTURERO

EN EL TOTAL NACIONAL, 1965-2016

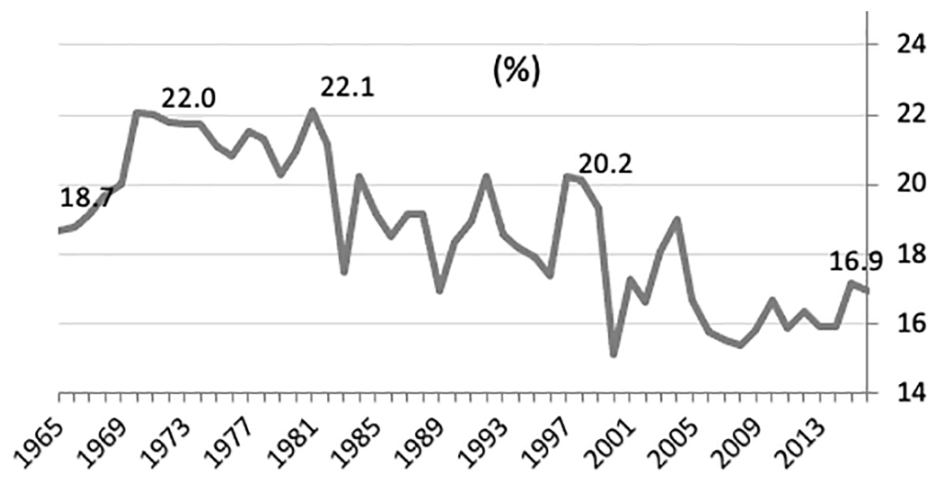

Fuente: elaborada con datos del World Bank (2019).

Para analizar la industria de Nuevo León conviene utilizar algunos elementos de su historia. Al respecto, en su libro El Grupo Monterrey, Abraham Nuncio - con referencias bíblicas sobre la creación- la explica del siguiente modo: "En el principio creó Don Eugenio la cerveza, y vio que la cerveza era buena, pero que le faltaba algo, y creo la fábrica de donde salieron las botellas para envasarla, y vio que era buena" (1982: 19). El autor analiza la importancia de la industria manufacturera regio- 
montana, pero enfatiza la capacidad de liderazgo de las familias Garza, Sada, Lagüera, Muguerza, Calderón y otras que crearon lo que por muchos años han sido los grupos industriales regiomontanos. La cervecería fue la empresa madre que hizo posible la acumulación capitalista creada en 1890, pero la metalurgia fue el eje central sobre el cual giró la industrialización.

Hablar de Nuevo León y en particular de Monterrey, su capital, conduce a la industria manufacturera cimentada en la industria siderúrgica iniciada con Fundidora de Fierro y Acero de Monterrey en 1903; a la cementera que dio origen a Cemex en 1906; a la vidriera, en 1909, que se convertiría en el corporativo Vitro; o a la de acero, que en la década de los cuarenta dio origen a la empresa Hylsa e Industrias Monterrey, S.A., productoras de lámina galvanizada, varilla corrugada, etc. (Cerutti, 2016). A partir de estas empresas pioneras se crearon un conjunto de subsidiarias regionales y nacionales que allanaron el terreno para la internacionalización de sus capitales. Estas empresas impusieron un patrón que ha identificado a la economía regional como la proveedora nacional por excelencia de un conjunto de bienes durables (actualmente llamados commodities) y servicios básicos para construir la infraestructura física necesaria para el desarrollo.

Para entender el desarrollo industrial de Nuevo León es necesario un análisis sistémico que considere los aspectos que explican el funcionamiento y éxito de la actividad industrial. En este sentido, Villareal y de Villarreal (2002) descomponen el enfoque sistémico en seis niveles: microeconómico, mesoeconómico, macroeconómico, internacional, institucional y político-social. En el nivel microeconómico se considera que las economías necesitan empresas flexibles que cuenten con multiproductos, multiprocesos y multihabilidades. Para sobrevivir a la competencia necesitan producir diversidad con múltiples tecnologías, cuya consecuencia es la necesidad de adquirir habilidades para dominar dichas tecnologías. La necesidad de competir en un mercado globalizado con una variedad de tecnologías en el nivel micro requiere una organización inteligente dentro de la empresa que fomente innovaciones y aprendizaje industrial. En tales condiciones, las economías del conocimiento toman mucho peso en la composición de los costos y los precios finales (Villarreal y de Villarreal, 2002: 134).

El enfoque sistémico incluye un sistema fiscal competitivo que respete la equidad y la eficiencia, pero que reduzca los costos de produc- 
ción de las empresas. Bajo estas condiciones, es posible que la industria pase a otro nivel de desarrollo que algunos identifican como una cuarta revolución industrial, o industria 4.0, donde existe una producción integrada de máquinas con las distintas unidades de producción, utilización de robots automatizados con alto nivel de inteligencia colaborativa, uso de internet de las cosas mediante sensores avanzados que identifiquen el desempeño de los robots, que incluye la conexión con los clientes para monitorear potenciales fallas del producto (Basco et al., 2018).

Sin restarle importancia a la época anterior a 1970, que significó tres cuartos de siglo de esfuerzos en múltiples direcciones, tanto en inversiones, como desarrollos tecnológicos, aprendizaje para exportar a los mercados internacionales, organización administrativa, etc., la época dorada de la industria regiomontana comprende desde mediados de la década de los setenta hasta principios de los ochenta. Las empresas de las familias Garza Sada, Sada Muguerza, Garza Lagüera, etc., se constituyeron en cuatro holdings: Alfa, Visa, Vitro y Cydsa para administrar más eficientemente sus capitales. Su poder económico fue incuestionable; pasaron a formar parte de la lista de las 500 empresas más grandes del mundo, con ventas superiores a los 100 mil millones de pesos y una plantilla del personal superior a las 175 mil personas (Nuncio, 1982: 22).

Tal vez por las políticas proteccionistas propias de la época, inducidas por el enfoque estructuralista de la CEPAL (Prebisch, 1986), Nuevo León logró especializarse en productos intermedios básicos para la industria. Como resultado de la especialización regional desde la década de los cuarenta, el grupo Vitro e Hylsamex incursionaron en la producción de bienes de capital y tecnología. Como toda actividad económica que se rige por ciclos de crecimiento y depresión, la industria básica, bajo la dirección de esas grandes empresas, fue golpeada por las crisis económicas de la década de los ochenta. Su alto crecimiento y expansión, al compás del auge petrolero durante la década de los setenta, les permitió endeudarse. Entre 1978-1981 se había acumulado una deuda externa neta de 47 mil 769 millones de dólares, de los que 16 mil 300 millones de dólares correspondían al sector privado (Vidal, 2000: 132; Pozas, 2002: 134).

En 1981, del financiamiento total, 32.5\% se concentró en tan sólo 10 grupos, encabezados por Alfa, Visa, Desc y Vitro, todas de Monterrey (Vidal, 2000: 134). Alfa fue la empresa que acumuló más compromisos 
con los acreedores, con cerca de 2 mil 700 millones de dólares, Visa, 2 mil 300 millones, Vitro, 600 millones, etc., hasta acumular una suma aproximada de 6 mil millones entre los principales grupos industriales de Monterrey (Pozas, 2002: 134). Este endeudamiento con la banca internacional y nacional de los grupos industriales del país, y propiamente de Monterrey, fue un medio para que el capital financiero internacional acrecentara sus ganancias. Vidal lo expone muy claro: "En los años anteriores [a la crisis] el crecimiento de la economía, los niveles de inversión alcanzados con el concurso de fondos públicos, el manejo tan amplio de las inversiones y las colocaciones financieras que dichos grupos realizaron, les permitieron hacerse de utilidades provenientes de las más diversas esferas económicas" (2000: 134).

Con la crisis de 1986, las empresas enfrentaron dificultades para pagar las deudas, se contrajo la inversión productiva, al mismo tiempo que se incrementó el costo de la deuda y su servicio; sin embargo, como lo señala Vidal, este endeudamiento no anuló la presencia ni propició el desmantelamiento de los grupos industriales regiomontanos (Vidal, 2000). Hylsamex, empresa del grupo Alfa en alianza con las empresas Sivensa, de Venezuela, y Usiminas, de Brasil, compraron la compañía paraestatal venezolana Sidor. Estos procesos globalizadores del capital regiomontano generaron deudas por mil 345 millones de dólares, que propiciaron problemas para el buen funcionamiento futuro de Hylsamex, que condujo a que el grupo Alfa la vendiera al grupo Techint en 2005 (Corrales, 2007). Si bien la venta de empresas importantes significó un duro golpe para los regiomontanos, éstas siguieron operando en mejores condiciones financieras y tecnológicas.

\section{MARCO METOdológico}

Aunque la desindustrialización se comprende como un proceso complejo en el que intervienen cuestiones económicas, políticas y sociológicas, desde el punto de vista de la economía aplicada es posible identificarla cuantitativamente. Para ello se van a emplear tres métodos. El primero consiste en identificar la desindustrialización a través de dos indicadores que midan la participación porcentual del empleo manufacturero en el empleo total (EM) y en el valor agregado total (VAM). En este caso, la caída de los indicadores en el periodo será evidencia de desindustrialización. El segundo método es el índice de 
cambio estructural de Schiavo-Campo (1978) que permite identificar la desindustrialización por medio de la velocidad del cambio estructural exhibido por la industria manufacturera, y con el tercero se determina si la desindustrialización ocurrida en el país fue prematura o natural. Para ello se relaciona el ingreso real per cápita con el porcentaje de participación máximo alcanzado por las manufacturas en el producto total. De acuerdo con Rodrik (2016), para determinar el grado de desindustrialización alcanzada se parte del hecho de que los países que transitaron a economías desindustrializadas después de la década de los noventa lo hicieron con ingresos reales per cápita promedio de 20 mil 537 dólares americanos (con base 1990) y con una participación de las manufacturas en la economía de 24.1 por ciento. Por lo tanto, estos valores se consideraron parámetros para determinar el grado de desindustrialización en México y Nuevo León.

Con el primer método se calcularon dos indicadores para medir la participación de la industria manufacturera en la economía en términos de empleo y valor agregado.

$$
E M=\frac{E M P L E O \text { man }}{\text { EMPLEO total }} 100
$$

Donde $E M$ representa la participación porcentual del empleo manufacturero en el total, el cual resulta de dividir el empleo manufacturero entre el empleo total multiplicado por 100.

$$
V A M=\frac{V A \text { Manufacturas }}{\text { VA total }} 100
$$

Donde VAM es la participación porcentual del valor agregado de las manufacturas en el total, que resulta de dividir el valor agregado de la industria (VA manufacturas) entre el valor agregado total de la economía (VA total) por 100. Estos dos indicadores reflejan el estado del sector industrial manufacturero respecto al resto de la economía y se espera que hayan tenido caídas a lo largo del periodo. El aumento en la productividad total de los factores tiende a desplazar a los trabajadores de los sectores más productivos a los menos productivos, lo que ocasiona que aumente la generación de empleos y de producción a mayores tasas en las actividades no manufactureras (Ngai y Pesarides, 2004). A lo largo del tiempo, este movimiento de trabajadores de un sector a otro 
se ve reflejado como una menor participación de las manufacturas en la economía. El desplazamiento de la fuerza laboral industrial hacia el sector terciario ocurre como resultado de la mayor productividad en la industria, la cual, se supone, emplea intensamente el capital y la tecnología. En países desarrollados se puede decir que la caída del empleo manufacturero es resultado del aumento de productividad.

Por el lado de la demanda, conforme aumenta el ingreso per cápita, los patrones de consumo de la población cambian, lo que ocasiona que el gasto en bienes tangibles sea cada vez menor en relación con los servicios. Al final, el cambio en el consumo propicia que se reduzca el precio relativo de las manufacturas (Lawrence y Edwards, 2013).

En teoría, el cambio estructural de la economía, de industrial a terciaria, aparece de manera natural y como resultado de un proceso de maduración de la industria. En un mundo globalizado, la producción de manufacturas se moverá y ocurrirá en los países que tengan la mayor ventaja comparativa. Cuando la desindustrialización no ocurre de manera natural, los países se enfrentan a una economía terciaria, pero con una base industrial débil que ocasiona que sus tasas de crecimiento económico sean lentas o se estanquen. A diferencia de otros sectores económicos, las manufacturas son clave para el crecimiento nacional, ya que son capaces de generar grandes cantidades de trabajo no calificado, utilizan procesos tecnológicamente dinámicos y no enfrentan una demanda restringida por su población, ya que el excedente de producción puede ser exportado. Para autores como Kaldor (1966), las manufacturas son el motor de crecimiento de la economía al promover los encadenamientos productivos con otros sectores.

El segundo metodo para identificar la desindustrializacion es el índice de cambio estructural (ICE), formulado por Schiavo-Campo (1978), ${ }^{2}$ el cual mide la velocidad del cambio estructural exhibido por la industria manufacturera, es decir, qué tan rapido ha ganado o perdido participación en la producción total. La fórmula del índice es la siguiente:

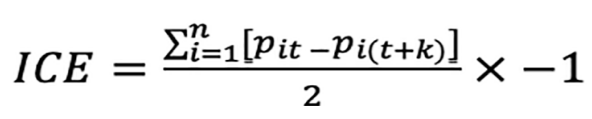

La fórmula original es ICE $=50 \sum_{\mathrm{i}=1}^{n}\left|p_{t}-p_{t+k}\right|$, que indica valores absolutos; sin embargo, no sólo nos interesa conocer la velocidad del cambio estructural sino también el signo para determinar si el cambio representa una pérdida o ganancia de participación en el rango de años; por ello no se usan valores absolutos para que los signos representen una ganancia $(+)$ o una pérdida (-). 


\section{Donde:}

$p_{\mathrm{i}}$ : representa la participación del valor agregado de las manufacturas en el PIB total. Los subíndices $t$ y $(t+k)$ indican el año inicial y final del intervalo. La fórmula consiste en la sumatoria de los valores de los cambios en la participación sobre el producto total de cada sector, dividido entre 2 para evitar un doble conteo. El resultado se multiplicó por menos uno, de esta forma si la participación de la industria en el PIB es menor en el año inicial $p_{i t}$ que en el final $p_{i(t+k)}$, el resultado tendrá signo positivo e indicará un cambio estructural positivo para la industria manufacturera. Un signo negativo expresará una pérdida de peso en la composición del producto.

Los índices y tasas se calcularon para un periodo de tres años, que comenzó en 1993 y terminó en 2016 con cifras deflactadas.

Finalmente, se aplicó el criterio de Rodrik para determinar si la desindustrialización alcanzada fue resultado de un proceso de industrialización madura o prematura. Para ello se calcularon los ingresos reales per cápita entre 1965 y 2016, y se relacionaron con la participación de las manufacturas en el valor agregado (VAM), para así compararla con los parámetros encontrados por Rodrik en economías desarrolladas que transitaron a la terciarización.

Las fuentes de información para calcular los tres indicadores descritos provienen de las bases del Sistema de Cuentas Nacionales y censos económicos 1994, 1999, 2004, 2009, 2014 y 2019 del INEGI, y de los indicadores de desarrollo del Banco Mundial en el periodo 1965 a 2016.

\section{RESUltados}

La desindustrialización es el resultado de una menor participación de las manufacturas en la producción total, lo cual puede ocurrir por diversas razones. Primero, se considera que conforme aumenta el ingreso ${ }^{3}$ se genera un cambio en las preferencias de los consumidores al reducir la demanda de alimentos y productos básicos, y aumentar la de otros bienes y servicios. Aunque Nuevo León aún mantiene una participación importante de las manufacturas en la economía (en términos de

Este fenómeno se atribuye a la ley de Engel que establece que la demanda de alimentos aumenta a menor velocidad que la demanda de consumo total (Chenery, 1982: 9). 
empleo y producto), la tendencia, al igual que sucede a nivel nacional, es hacia la baja. En la Figura 2 se presenta la trayectoria de las manufacturas de Nuevo León y de México en términos de su participación en el valor agregado real (VAM) de 1993 a 2017. Resalta el hecho de que las manufacturas en Nuevo León tuvieron una mayor participación en valor agregado estatal en comparación con el promedio nacional. En 1996, la industria regiomontana registró el mayor porcentaje de participación con $28.5 \%$ y se mantuvo arriba de $25 \%$ después de ese año. Si tomamos en cuenta este indicador, se podría afirmar que la desindustrialización empieza a partir de 1996.

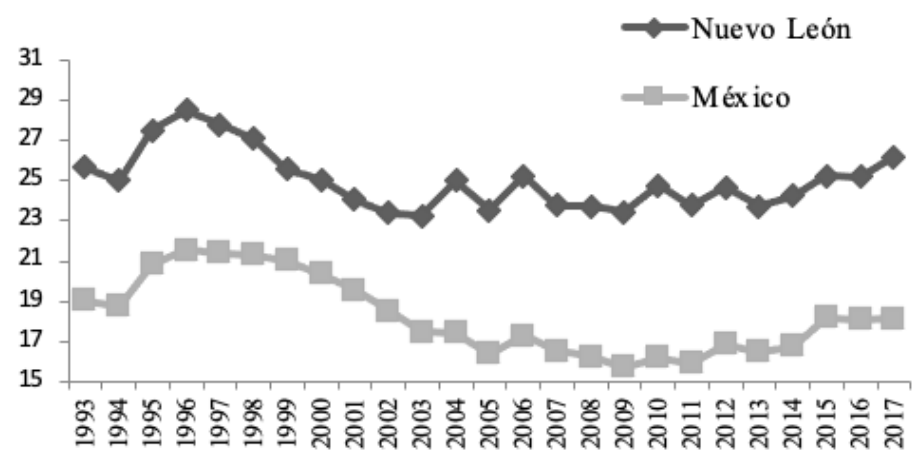

Fuente: elaborada con datos del SCN, INEGI.

En cuanto a la participación de las manufacturas en el empleo, encontramos que en Nuevo León se registró mayor participación que a nivel nacional, que alcanzó una cifra máxima de $37.1 \%$ en 1998 , y aunque ha perdido importancia en la generación de empleos, de acuerdo con los censos económicos del INEGI, todavía en 2018 representaba arriba de 30 por ciento. En la Figura 3 se muestra que, si tomamos como referencia la participación del empleo manufacturero en el total (EM), entonces la desindustrialización ocurre a partir de 1998. Sobresale el hecho de que, de acuerdo con Rodrik, los países que empiezan a desindustrializarse después de los noventa lo hacen con tasas de participación de las manufacturas en el empleo de 18.9\% (2016: 23). Sin embargo, 
en el caso de México, la desindustrialización ocurre a partir de una tasa máxima de $30.2 \%$ promedio nacional y $37.1 \%$ en Nuevo León.

FIGURA 3

TRAYECTORIA DE LA EM

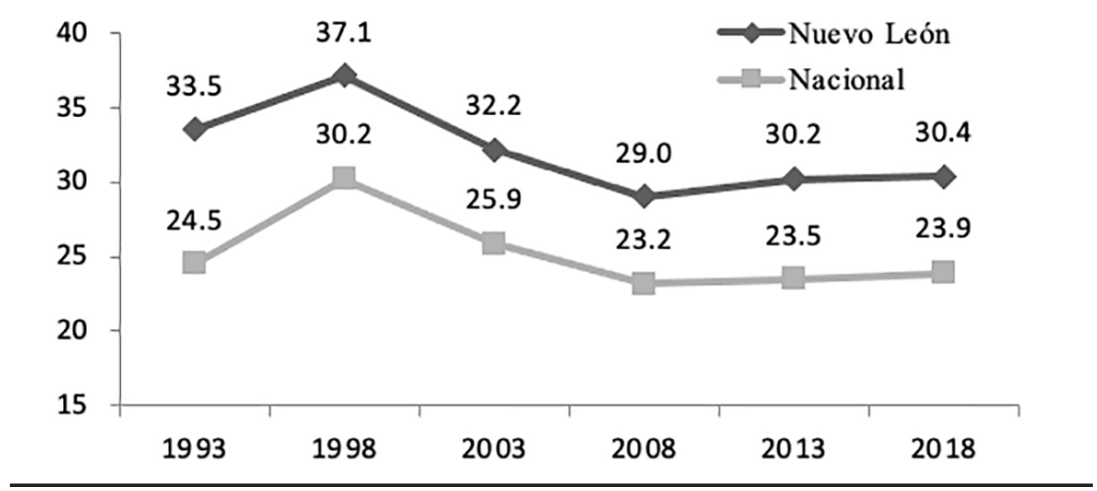

Fuente: elaborada con datos de los censos económicos del INEGI.

En el análisis de la industria de Nuevo León es importante tomar en consideración la heterogeneidad y el desempeño de cada una de las 22 actividades que la integran, pues permite poner en contexto el futuro de esta industria y el riesgo que implica generalizar a partir del comportamiento promedio. En el Cuadro 1 se presenta la trayectoria de las 22 industrias que integran las manufacturas y su participación en el valor agregado real (VAM) (entre 2003 a 2016). Las dos últimas columnas contienen el cambio porcentual entre 2003-2016 en Nuevo León y en México. Lo que encontramos es que, mientras algunas industrias regiomontanas han perdido participación en el valor agregado y en el empleo, y su desaparición debido a la desindustrialización parece inevitable, otras industrias presentaron tasas de crecimiento positivas. Son éstas últimas las industrias que presentan mayor intensidad en el uso de tecnología y que emplean además personal más calificado.

A pesar de la importancia de la industria en la economía de Nuevo León, en general el cambio estructural ha sido más intenso que el promedio nacional. Por ejemplo, entre 2003 y 2016, la industria manufacturera de Nuevo León perdió 3.4 puntos porcentuales en el valor agregado real, cifra superior a la pérdida de la industria nacional, que 
fue de 1.29 puntos porcentuales. Las actividades con la mayor pérdida fueron los productos derivados del petróleo y carbón, la industria química y la fabricación de plásticos y hules (324-326), las cuales registraron una caída de 1.68 puntos porcentuales. Otra industria importante fue la de bebidas y tabaco (312), que perdió 0.96 puntos y que incluye a una de las empresas cerveceras más importantes del estado.

\section{CUADRO 1}

VAM REAL DE NUEVO LEÓN Y CAMBIO ESTRUCTURAL

PERIODO 2003-2016

\begin{tabular}{|c|c|c|c|c|c|c|c|}
\hline & & & & & & \multicolumn{2}{|c|}{ Cambio 2003-2016 } \\
\hline Concepto & 2003 & 2005 & 2010 & 2015 & 2016 & $\begin{array}{l}\text { Nuevo } \\
\text { León }\end{array}$ & México \\
\hline Valor agregado bruto (millones pesos, 2013) & 803889 & 885439 & 1025184 & 1219287 & 1238927 & & \\
\hline Participación porcentual (\%) & 100 & 100 & 100 & 100 & 100 & $\%$ & $\%$ \\
\hline Industrias manufactureras & 26.6 & 26.2 & 25.3 & 23.3 & 23.2 & -3.4 & -1.29 \\
\hline 311 - Industria alimentaria & 3.7 & 3.5 & 3.6 & 3.2 & 3 & -0.65 & -0.25 \\
\hline 312 - Industria de las bebidas y tabaco & 2.8 & 2.3 & 1.9 & 1.6 & 1.9 & -0.96 & 0.09 \\
\hline 313-314 - Fabricación de insumos y textiles & 0.3 & 0.3 & 0.2 & 0.2 & 0.1 & -0.15 & -0.11 \\
\hline $\begin{array}{l}\text { 315-316 - Fabricación de prendas de vestir; } \\
\text { Curtido y acabado de cuero y piel }\end{array}$ & 0.5 & 0.5 & 0.4 & 0.4 & 0.3 & -0.18 & -0.18 \\
\hline 321 - Industria de la madera & 0.1 & 0.1 & 0.1 & 0.1 & 0.1 & 0 & -0.04 \\
\hline 322-323 - Industria del papel & 0.7 & 0.7 & 0.6 & 0.6 & 0.6 & -0.1 & -0.01 \\
\hline $\begin{array}{r}\text { 324-326 - Productos derivados del petróleo y el } \\
\text { carbón; Industria química, del plástico y del } \\
\text { hule }\end{array}$ & 4.2 & 3.6 & 3.6 & 2.8 & 2.5 & -1.68 & -0.91 \\
\hline 327 - Productos a base de minerales no metálicos & 1.3 & 1.4 & 1.2 & 1.1 & 1.1 & -0.28 & -0.04 \\
\hline $\begin{array}{l}\text { 331-332 - Industrias metálicas básicas; } \\
\text { Fabricación de productos metálicos }\end{array}$ & 4.7 & 5 & 4.7 & 4.4 & 4.4 & -0.29 & -0.49 \\
\hline $\begin{array}{r}\text { 333-336 - Fabricación de maquinaria y equipo; } \\
\text { equipo de computación, comunicación, } \\
\text { componentes electrónicos; aparatos eléctricos y } \\
\text { equipo de energía eléctrica; Fabricación de } \\
\text { equipo de transporte. }\end{array}$ & 7.2 & 7.6 & 7.9 & 8.2 & 8.5 & 1.32 & 0.7 \\
\hline 337 - Fabricación de muebles & 0.4 & 0.4 & 0.3 & 0.3 & 0.2 & -0.16 & -0.08 \\
\hline 339 - Otras manufactureras & 0.7 & 0.7 & 0.8 & 0.4 & 0.5 & -0.27 & 0.04 \\
\hline
\end{tabular}

Nota: Producto Interno Bruto Trimestral. Precios de 2013.

Fuente: elaborado con datos del INEGI, SCN.

En el Cuadro 1 también es posible identificar las industrias que han mantenido, e incluso aumentado, su participación en el valor agregado real de Nuevo León. Por ejemplo, las agrupadas en la clasificación 333-336: las fábricas de maquinaria y equipo; de equipo de computación, comunicación, medición y de otros equipos, de componentes y accesorios electrónicos; de accesorios, de aparatos eléctricos y equipo de generación de energía eléctrica; y las de equipo de transporte. Todas ellas generan arriba de 7\% del valor agregado total, además de que su participación aumentó 1.3 puntos porcentuales de 2003 a 2016. El 
análisis del cambio estructural sugiere que la desindustrialización en Nuevo León ha dado lugar a un reacomodo de las actividades manufactureras, de tal forma que las que son menos intensivas en capital y tecnología (alimentos, muebles, plásticos, productos metálicos y no metálicos) han perdido participación en el valor agregado, mientras que las más competitivas y con mayor poder de adaptación, y que además están orientadas al mercado internacional (maquinaria y equipo, computación, aparatos eléctricos y equipo de transporte), son las que sostienen el crecimiento de la industria regiomontana.

En términos de valor agregado, las industrias más grandes son la fabricación de equipo de transporte (336), productos metálicos (332), industria alimentaria (311), industria metálica (331) e industria de bebidas y tabaco (312). En 2018, juntas generaron más de 60\% del valor agregado manufacturero del estado. La industria de equipos de transporte es la más sobresaliente al generar la mayor aportación al valor agregado (25\%) y además incrementar su participación a lo largo del periodo. Esta tendencia confirma la hipótesis de que la industria regiomontana se ha reconfigurado a favor de productos de bienes y servicios con un mayor valor agregado y complejidad tecnológica. Esta mentalidad empresarial ha colocado en un segundo plano a la industria tradicional y básica como la del hierro y acero, el cemento, vidrio y bebidas en la región.

A través del cálculo del índice de cambio estructural (ICE) se identificó la velocidad del cambio estructural de las manufacturas a nivel nacional y en Nuevo León, entre 1993 y 2016. El ICE implica obtener tasas de crecimiento en periodos de tres años para ver la evolución de la tasa a lo largo de diferentes periodos. Generalmente se asocia el crecimiento de las manufacturas con el crecimiento de la producción total, por los encadenamientos que genera con otros sectores productivos, por esta razón también se calcularon las tasas de crecimiento del PIB para identificar dicha asociación (Cuadro 2). 
CUADRO 2

ÍNDICE DE CAMBIO ESTRUCTURAL (ICE) Y CRECIMIENTO ANUAL DEL PIB NACIONAL Y NUEVO LEÓN (1993-2016)

\begin{tabular}{lcccc}
\hline Periodo 3 años & ICE \% & $\begin{array}{c}\text { Nacional } \\
\text { PIB, tasa anual }\end{array}$ & $\begin{array}{c}\text { ICE } \\
\%\end{array}$ & PlB, tasa anual \\
& & & 0.91 & -2.4 \\
$\mathbf{1 9 9 3 - 1 9 9 5}$ & 0.91 & -3.6 & -0.71 & 5.1 \\
$\mathbf{1 9 9 6 - 1 9 9 8}$ & -0.12 & 3.9 & $\mathbf{- 0 . 7 6}$ & $\mathbf{4 . 5}$ \\
$\mathbf{1 9 9 9 - 2 0 0 1}$ & $-\mathbf{0 . 7 3}$ & $\mathbf{3 . 4}$ & 0.80 & 10.8 \\
$\mathbf{2 0 0 2 - 2 0 0 4}$ & -0.55 & 6.4 & 0.13 & 5.4 \\
$\mathbf{2 0 0 5 - 2 0 0 7}$ & 0.07 & 3.9 & 0.53 & -0.1 \\
$\mathbf{2 0 0 8 - 2 0 1 0}$ & -0.02 & -0.5 & -0.02 & 0.9 \\
$\mathbf{2 0 1 1 - 2 0 1 3}$ & 0.29 & 0.9 & 0.47 & 3.4 \\
\hline $\mathbf{2 0 1 4 - 2 0 1 6}$ & 0.67 & 2.6 & & \\
\hline
\end{tabular}

Nota: precios de 2013.

Fuente: elaborado con datos del INEGI, SCN.

En general, ni a nivel nacional ni en Nuevo León se distingue una relación clara entre crecimiento del PIB y el índice de cambio estructural (ICE) que nos permita afirmar que los cambios positivos en la participación de las manufacturas están asociados a un mayor crecimiento económico o viceversa. En algunos años, cuando el ICE fue negativo, el crecimiento del PIB fue positivo (por ejemplo, entre 1996-2004 a nivel nacional). Lo que sí muestran los datos es que los cambios estructurales, así como las tasas de crecimiento del PIB fueron más pronunciados durante los primeros cuatro trienios, es decir, entre 1993-2004, tanto a nivel nacional como en Nuevo León. Esto quiere decir que el mayor cambio estructural en las manufacturas se presentó alrededor del 2000.

En el trienio 1993-1995, que captura el efecto de la crisis económica desencadenada por la devaluación del peso, el ICE muestra un valor positivo de 0.91 , pero el crecimiento del PIB fue negativo para México y Nuevo León, lo cual podría deberse a que la crisis económica generó una contracción en el comercio y los servicios, pero no en las manufacturas. Durante la crisis, las manufacturas aumentaron su participación en la producción quizás como resultado del aumento de su competitividad internacional, ya que la demanda de exportaciones se aceleró por la devaluación del peso ante el dólar estadounidense (Lechuga y Gutiérrez, 2015; Dussel y Ortiz, 2015). Durante el trienio 1999-2001, la industria manufacturera a nivel nacional registró la mayor caída en su tasa de crecimiento (-0.73), lo cual también ocurrió en Nuevo León, incluso con una caída más pronunciada (-0.76). Para el siguiente trienio 
(2002-2004) se observó una recuperación rápida de la industria regiomontana, pues el cambio estructural de las manufacturas (0.8) y la tasa de crecimiento anual del PIB (10.8\%) fueron positivas.

El cálculo del ICE nos permite comprobar que la desindustrialización de México, y evidentemente en Nuevo León, se profundiza y alcanza su mayor nivel en el trienio 1999-2001. Sin embargo, se puede destacar que el estado mantuvo en promedio índices positivos y cuantitativamente mayores que el promedio nacional, así como también tasas positivas de crecimiento del PIB. La especialización industrial que lo identificó durante décadas como importante proveedor de todo tipo de commodities y productos finales para la economía mexicana, desde acero, hasta cemento y polímeros, pasando por motores eléctricos y productos electrónicos, permitió que este estado contara con una base industrial sólida para transitar a una industria moderna y automatizada.

Finalmente, para determinar si la desindustrialización en México, y en específico en Nuevo León, fue prematura o resultado de un proceso de maduración, se relacionó el ingreso per cápita con el porcentaje de participación más alto alcanzado por la industria en el valor agregado real y se comparó con parámetros internacionales. Por ejemplo, Castillo y Martins (2016) estudiaron una muestra de 100 países y encontraron que el ingreso per cápita alcanzado al inicio de la desindustrialización fue de 15 mil 500 dólares (precios de 2015). En este trabajo se consideró el criterio de Rodrik (2016), quien estimó los valores alcanzados por las economías desarrolladas que transitaron a una economía terciaria y cuyo proceso fue resultado de una maduración de la industria. El ingreso per cápita en el punto más alto de participación de las manufacturas en el valor agregado total (24.1\%) fue igual a 20 mil 537 dólares (base 1990). Por lo tanto, se calculó el ingreso per cápita real de México y se relacionó con la participación del VAM calculado a nivel nacional (Figura 4). Con datos del Banco Mundial, encontramos que México habría alcanzado su máximo nivel de industrialización en el año 2000 con $18 \%$ de participación manufacturera en el valor agregado total y con un ingreso per cápita de 8 mil 806 dólares (base 2010) u 8 mil 702 dólares (base 1990). La contribución de las manufacturas al valor agregado en México se reduce cada vez más, lo que podría ser indicativo de que la industria manufacturera se está especializando en sectores menos productivos o con menor intensidad tecnológica. 


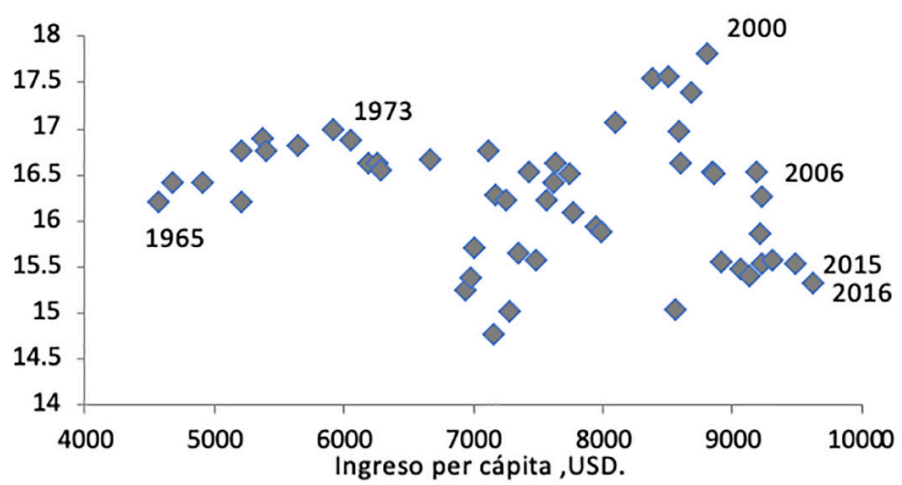

Nota: precios de 2010.

Fuente: elaborada con datos del World Bank (2019).

La evidencia indica que México se enfrenta a un proceso de desindustrialización prematura con participación de las manufacturas e ingreso per cápita menor a los logrados por otros países que ya transitaron a una economía terciaria y cuya desindustrialización fue resultado de un proceso natural de maduración.

Aunque después del año 2000, el ingreso real per cápita se ha incrementado, la participación de las manufacturas en el valor agregado a nivel nacional se está reduciendo. Sin embargo, en el caso de Nuevo León encontramos que, en el año 2000, el porcentaje de participación de las manufacturas en el valor agregado alcanzó $25 \%$ y el ingreso per cápita real fue de 12 mil 633 dólares. Esto quiere decir que el pico de industrialización de Nuevo León se ubicó arriba, no sólo del porcentaje de participación nacional (18\%), sino del referente mundial calculado por Rodrik $(24.1 \%)$, lo cual indica que existe un proceso de desindustrialización madura. Se puede afirmar que la terciarización actual de la economía regiomontana se dio después de consolidar una base industrial. 


\section{CONCLUSIÓN}

En este trabajo encontramos que la desindustrialización en México y en Nuevo León se empieza a gestar a finales de los años noventa, cuando se alcanzan los picos máximos de participación de las manufacturas en el valor agregado real y en la generación de empleos. En general, la caída en la participación de las manufacturas en la economía nacional indica que la desindustrialización de México se presentó sin que se lograra consolidar el desarrollo de la industria manufacturera, que había sido el motor de crecimiento; por lo tanto, la interrupción del desarrollo industrial se puede caracterizar como una desindustrialización prematura. A diferencia de la experiencia nacional, en Nuevo León la desindustrialización ocurre a partir de una mayor participación de la industria manufacturera en la economía estatal y con un ingreso real per cápita más alto. Estas características indican que la desindustrialización en Nuevo León fue resultado de un proceso de maduración en el que las actividades industriales tradicionales (de vidrio, acero y cemento) de la región perdieron participación en el estado, pero cedieron su lugar a industrias más modernas (como la electrónica, eléctrica, autopartes, etc.) que cuentan con alta capacidad para generar valor agregado y empleo.

El análisis de las manufacturas a tres dígitos confirma la contracción del componente industrial en la economía de Nuevo León, sin que esto signifique su desaparición o la tercerización total de la economía. Al contrario, el cambio estructural entre los años 2003-2016 ofrece evidencia de que las actividades tradicionales, intensivas en trabajo y basadas en el uso de recursos naturales de la región han tenido las mayores pérdidas de participación en el producto; sin embargo, las industrias con contenido de tecnología, intensivas en capital y orientadas al mercado externo (industria automotriz) son las que mantienen una participación creciente en la industria manufacturera y, por lo tanto, en la producción total. Estos hallazgos refuerzan los argumentos a favor de la industrialización como origen y destino de la industria regional y apoyan los esfuerzos por introducir la industria 4.0 por autoridades de fomento económico y grupos empresariales.

Se considera que, en el futuro, la desindustrialización va a dar lugar no a una economía terciarizada, sino a una industria adaptada a las nuevas condiciones de competencia a través de la implementación 
de nuevos procesos de producción que añadan formas innovadoras de organización, comercialización y producción, con mejores vínculos tecnológicos y de globalización de datos. En esta nueva visión, la producción manufacturera no está limitada al mercado local sino al global, mediante el uso de las redes mundiales de comunicación. En el caso de Nuevo León, desde 2017 se han introducido acciones para fomentar el enfoque multivariado en tecnologías y esquemas de organización para la producción de bienes y servicios. Encabeza la estrategia el Consejo Nuevo León, a través de la Secretaría de Economía y Trabajo, cuyo objetivo general es fomentar e impulsar a múltiples empresas para alcanzar ese nivel de desarrollo industrial 4.0 (Gobierno de Nuevo León, 2017).

\section{REFERENCIAS}

Abasco, Ana Inés, Gustavo Beliz, Diego Coatz y Paula Garnero (2018), Industria 4.0 Fabricando el Futuro, Unión Industrial Argentina / BID / INTAL, Buenos Aires.

Camacho, José Antonio y Alexander Maldonado (2018), "De la desindustrialización madura a la desindustrialización prematura: la dinámica e inflexión del debate teórico", Investigación Económica núm. 303, vol. LXXVII, Ciudad de México.

Castillo, Mario y Antonio Martins (2016), Premature deindustrialization in Latin America, ECLAC / Naciones Unidas / German Cooperation / Deutsche Zusammenarbeit, Santiago.

Cerutti, Mario (2000), Propietarios, empresarios y empresas en el norte de México. Monterrey: de 1848 a la globalización, Siglo XXI, México.

Cerutti, Mario (2016), "El gran empresariado de Monterrey (1848-2007). Una semblanza histórica", en J.C. López y Mario Cerutti (eds.), Historia económica y empresarial. México-Colombia, siglos XIX y XX, Universidad EAFIT / UANL, Medellín.

Chenery, Hollins B. (1982), Industrialization and Growth, the experience of large countries, Staff Working Papers, num. 539, Washington, DC.

Corrales, Salvador (2007), "Alianzas, fusiones y adquisiciones en la industria siderúrgica”, Economía y Sociedad, vol. XII, núm. 20, Morelia, México.

Dasgupta, Sukti y Singh, Aijt (2006), "Manufacturing, Services and Premature Deindustrialization in Developing Countries", Research No. 2006/49, ONU, World Institute for Development Economics, Helsinki, Finland.

Dussel, Enrique y Samuel Ortiz (2015), Monitor de la Manufactura Mexicana, UNAM 10, núm. 11, México. <https://www.dusselpeters.com/monitor11. pdf> [4 de marzo de 2017]. 
Gobierno de Nuevo León (2017), "Estado Inteligente Nuevo León 4.0”. $<$ http://www.nl.gob.mx/sites/default/files/presentacion_nl40_31_mayo_rev_02_2_0.pdf $>$ [5 de marzo de 2017].

INEGI (Instituto Nacional de Estadística y Geografía), Censos Económicos 1994, 1999, 2004, 2009, 2014 y 2018. <https://www.inegi.org.mx/datos/ default.html\#Programas $>$ [5 de marzo de 2020].

INEGI (Instituto Nacional de Estadística y Geografía), Sistema de Cuentas Nacionales 2003-2016. Estadísticas económicas sobre Nuevo León. < https:// www.inegi.org.mx/datos/default.html\#Programas $>$ [5 de marzo de 2017].

Kaldor, Nicholas (1966), Causes of the Slow Rate of Economic Growth of the United Kingdom: An Inaugural Lecture, London, Cambridge University Press, $40 \mathrm{p}$.

Kaufman, Daniel y Aleksander Kaliberda (1996), Integrating the unofficial economy into the dynamics of post-socialist economies, a framework of analysis and evidence, The World Bank, Washington, DC.

Lawrence, R. Z. y L. Edwards (2013), US Employment deindustrialization: Insights from history and the international experience, Washington, DC, Peterson Institute for International Economics, Policy Brief No. PB13-27.

Lechuga, Jesús y Abdiel Gutiérrez (2015), "La economía mexicana, un lento proceso de reestructuración”, Economía Informa, 392, pp. 47-64. <https:// doi.org/10.1016/j.ecin.2015.05.011>.

Mcmillan, Margaret, Dani Rodrik e Inigo Verduzco-Gallo (2014), “Globalization, Structural Change, and productivity Growth with an Update on Africa", World Development, Elsevier, vol. 63.

Ngai, L. Rachel y Christopher Pissarides (2004), "Structural change in a multisector model of growth", American Economic Review, London School of Economics.

Nuncio, Abraham (1982), El Grupo Monterrey, Nueva Imagen, México.

Palma, José Gabriel (2005), “Four Sources of 'De-Industrialization' and a New Concept of the "Dutch Disease"” en José Antonio Ocampo (ed.), Beyond Reforms Structural Dynamics and Macroeconomic Vulnerability, ECLAC / Standford University.

Pozas, María de los Ángeles (2002), Estrategia internacional de la gran empresa mexicana en la década de los noventa, El Colegio de México, México.

Prebisch, Raúl (1986), “El desarrollo económico de la América Latina y algunos de sus principales problemas", Desarrollo Económico, vol. 26, núm. 103, Santiago.

Rivera, L. (2014), "Contrabando de productos en México provoca pérdidas de casi 30 mil mdp: SAT", La Jornada, México. <http://www.jornada.unam. $\mathrm{mx} /$ ultimas/2014/10/08/contrabando-de-productos-en-mexico-provocaperdidas $>$ [5 de marzo de 2017]. 
Rodrik, Dani (2016), "Premature Deindustrialization", Journal of Economic Growth, vol. 21, pp. 1-33. <doi 10.1007/s10887-015-9122-3>.

Rowthorn, Robert y Ramana Ramaswamy (1997), “Deindustrialization: Its Causes and Implications", IMF Working Papers 97(42). < doi 10.5089/9781451975826.001>.

Schiavo-Campo, S. (1978), The simple measurement of structural change: a note, Suva, University of the South Pacific, Fiji.

Schneider, F., A. Buehn y C. Montenegro (2010), "Shadow economies all over the world, new estimates for 162 countries from 1999 to 2007', The World Bank, Washington, DC, <www.gfintegrity.org/storage/gfip/documents/ reports/world_bank_shadow_economies_all_over_the_world.pdf $>$ [5 de marzo de 2017].

Silva-Colmenares, J. (2014), "En torno a la discusión sobre 'desindustrialización', un sucinto análisis respecto a la producción bruta y el producto interno bruto", Tendencias, vol. XV. núm. 1, Pasto Nariño, Colombia.

Tregenna, Fiona (2009), "Characterising deindustrialisation: an analysis of changes in manufacturing employment and output internationally", Cambridge Journal of Economics, vol. 33, núm. 3. pp. 433-466.

Vázquez, L. (2017), "Revisión del modelo de sustitución de importaciones: vigencia y algunas reconsideraciones", Economía Informa, vol. 404, Ciudad de México.

Vidal, G. (2000), Grandes Empresas, Economía y Poder en México, Plaza y Valdés / UAM, México.

Villarreal, R. y R. De Villarreal (2002), México Competitivo 2020. Un modelo de competitividad sistémica para el desarrollo, Océano, México.

World Bank (2019), "World Development Indicators". <http://datatopics. worldbank.org/world-development-indicators/themes/economy.html $>\quad[5$ de marzo de 2017]. 